The high correlation between the degree of hypoxia and both T.C.T. and F.D.P. levels indicates that these are useful tests in the evaluation of the clotting status of a newborn infant. The two tests are interdependent, but whereas it is possible to do the T.C.T. in minutes, estimation of F.D.P. takes several hours.

Despite the pronounced impairment of the clotting state of these infants, there was no overt evidence of haemorrhage. Nevertheless, it cannot be assumed that such infants escape unscathed from the hypoxic episode, since the very process which caused the consumption of coagulation factors results in deposition of fibrin, and this may have led to damage of vital organs such as the brain. That damage can result is suggested by a recent report (Bryant et al., 1970) and further work is being conducted in this centre to evaluate this possible effect.

We acknowledge the co-operation willingly given at all times by Sister E. Owen and the nursing staff of the special care unit. The work was carried out while one of us (M.A.C.) had tenure of a research scholarship from the Wellcome Trust, and another (S.M.M.) was in receipt of a grant from the Clinical Research
Board of the University Hospital of Wales (Cardiff) Hospital Management Committee.

\section{References}

Aballi, A. J., and de Lamerens, S. (1962). Pediatric Clinics of North America, 9, 785 .

Bang, N. U. (1961). Thrombosis et Diathesis Haemorrhagica, 6, Suppl. No. 1, p. 262

Berglund, G. (1970). Acta paediatrica Scandinavica, 59, 664

Bryant, G. M., Gray, O. P., Fraser, A. J., and Ackerman, A. (1970). British Medical fournal, 4, 707.

Butler, N. R., and Bonham, D. G., (1963). Perinatal Mortality. London, Livingstone.

Chessells, J. M., and Wigglesworth, J. S. (1970). Archives of Disease in Childhood, 45, 539.

Crowell, J. W., Sharpe, G. P., Lambright, R. L., and Read, W. L., (1955). Surgery, 38, 696 .

Gray, O. P., Ackerman, A., and Fraser, A. J. (1968). Lancet, 1, 545

Gröntoft, O. (1953). Acta obstetricia et gynecologica Scandinavica, 32, 308. Haller, E. S., Nesbitt, R. E. L., and Anderson, G. W. (1956). Obstetrical and Gynecological Survey, 2, 179.

Hathaway, W. E., Mull, M. M., and Pechet, G. S. (1969). Pediatrics, 43, 233.

Merskey, C., Kleiner, G. J., and Johnson, A. J. (1966). Blood, 28, 1.

Murakami, M., et al. (1965). Fapanese fournal of Clinical Pathology, 13, 542.

Wefring, K. W., (1962). Fournal of Pediatrics, 61, 686.

\title{
Comparative Nephrotoxicity of Aspirin and Phenacetin Derivatives
}

\author{
I. C. CALDER \\ C. C. FUNDER, \\ C. R. GREEN, \\ K. N. HAM, J. D. TANGE
}

British Medical fournal, 1971, 4, 518-521

\section{Summary}

Both aspirin and phenacetin derivatives were shown to be nephrotoxic when administered to rats as a single intravenous injection. Phenacetin derivatives tended to produce more severe renal damage and to be nephrotoxic in smaller doses than aspirin derivatives. With the exception of a single derivative, the renal lesions were confined to the proximal convoluted tubule, even after administration of compounds which under other conditions have induced renal papillary necrosis.

\section{Introduction}

Though an association between abuse of analgesics and renal damage has been recorded many times by groups of observers from different countries, the processes causing the renal lesions are not known, and there is not even agreement regarding the identity of the analgesic compound responsible for the damage (Koutsaimanis and de Wardener, 1970; Nanra and Kincaid-Smith, 1970). Since the acute effects of these compounds on the mammalian nephron can be conveniently assessed after intravenous administration in rats (Green, Ham, and Tange, 1969), this experimental method has been used to compare the nephrotoxicity of aspirin and phenacetin derivatives.

University of Melbourne, Melbourne, Australia

I. C. CALDER, PH.D., Lecturer in Organic Chemistry

C. C. FUNDER, M.B., B.S., N.H. and M.R.C. Research Scholar

C. R. GREEN, PH.D., Reader in Pathology

K. N. HAM, M.D., PH.D., Lecturer in Pathology

J. D. TANGE, M.R.C.P., F.R.A.C.P., Senior Lecturer in Pathology

\section{Methods}

Female hooded rats, weighing about $200 \mathrm{~g}$, were divided into groups of five animals and individually marked. They were given tap-water to drink and a pellet diet.

Compounds under investigation were injected as the hydrochloride or as the sodium salt (Tables I and II). Single intravenous injections of $1 \mathrm{ml}$ or less were given, and the dose and concentration were determined in preliminary experiments, which also allowed assessment of the maximum dose compatible with survival. Animals were lightly anaesthetized with ether for tail vein injection and were killed by bleeding under ether anaesthesia 48 hours later. The kidneys were removed, fixed in $10 \%$ neutral formalin, and processed by routine methods for light microscopy.

Twenty-two compounds were tested, all on groups of five animals. Some compounds were tested at several dose levels (Tables I and II). Compounds were either commercially available or were synthesized by standard techniques and all samples purified before use.

Total $p$-aminophenol was estimated after hot acid hydrolysis and $\mathrm{O}$-conjugated $p$-aminophenol was estimated after hydrolysis with glusulase. $p$-Aminophenol was determined by the indophenol colorimetric method (Tompsett, 1969). Two groups, each of five rats, were used as controls, and these animals were given a single intravenous injection of $1 \mathrm{ml}$ of sterile normal saline.

\section{Results}

The nephrotoxic effect of these aspirin and phenacetin derivatives was manifest as necrosis of the proximal convoluted tubule. With the exception of the coincident renal papillary necrosis produced by $m$-aminosalicylic acid, this was the only lesion found in the experiment. Four grades of proximal 
convoluted tubule necrosis were distinguished: grade 1, necrosis of individual cells, or of groups of cells, but not of all cells in adjoining tubules (Fig. 1); grade 2, necrosis of all or most cells in adjoining tubules, but with viable tubules separating groups of necrotic tubules (Fig. 2); grade 3, a band of necrosis situated in the inner cortex, denoting necrosis of the distal

TABLE I-Nephrotoxicity of Phenacetin Derivatives

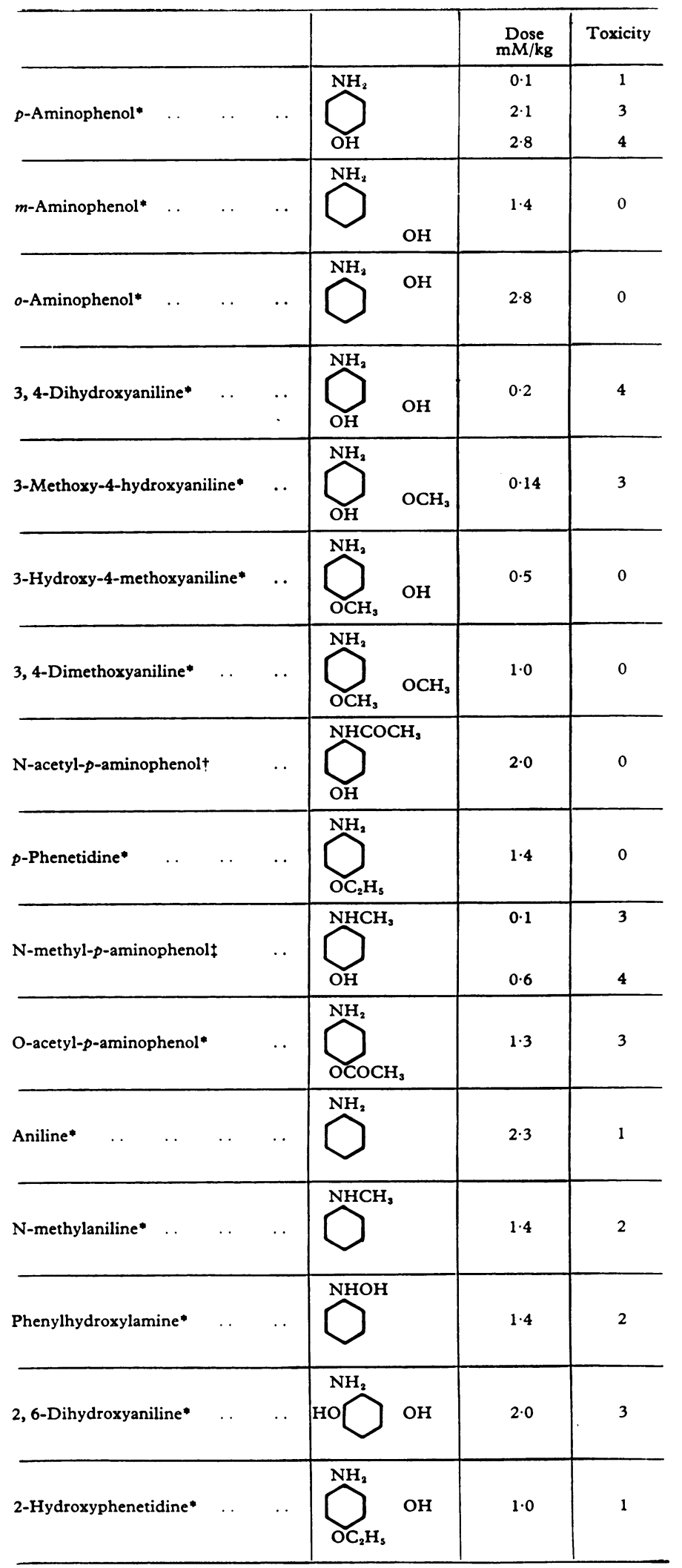

- Administered as hydrochloride. $\dagger$ Administered as sodium salt. $\ddagger$ Administered as sulphate.
TABLE II-Nephrotoxicity of Aspirin Derivatives

\begin{tabular}{|c|c|c|c|c|c|c|c|}
\hline & & & & & & $\begin{array}{c}\text { Dose } \\
(\mathrm{mM} / \mathbf{k g})\end{array}$ & Toxicity \\
\hline Aspirin* & $\ldots$ & $\ldots$ & $\ldots$ & $\ldots$ & . & \multirow{5}{*}{$\begin{array}{l}\left\{\begin{array}{l}4 \\
3.7 \\
5 \\
5.7\end{array}\right. \\
\left\{\begin{array}{l}1.4 \dagger \\
2.8 \\
5.7 \\
5.7 \\
4.5\end{array}\right.\end{array}$} & \multirow{5}{*}{$\begin{array}{l}2 \\
2 \\
2 \\
0 \\
2 \\
2 \\
2 \\
0 \\
0\end{array}$} \\
\hline Sodium salicylate ${ }^{*} \ldots$ & . & . & . & .. & . & & \\
\hline p-Aminosalicylic acid* & . & . & . & . & . & & \\
\hline m-Aminosalicylic acid* & . & . & . & . & . & & \\
\hline \multicolumn{2}{|c|}{$\begin{array}{l}\text { 2-4-Dihydroxybenzoic acid* } \\
\text { 2-5-Dihydroxybenzoic acid* }\end{array}$} & 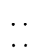 & $\begin{array}{l}\cdots \\
\cdots\end{array}$ & $\begin{array}{l}\cdots \\
.\end{array}$ & $\begin{array}{l}. . \\
\therefore\end{array}$ & & \\
\hline
\end{tabular}

*Administered as sodium salt.

† Omitted from Fig. 5.

third of all proximal convoluted tubules (Fig. 3); and grade 4, necrosis of the whole proximal convoluted tubule (Fig. 4).

With the exception of animals with grade 4 lesions, which died in anuria, the rats remained in good general condition after injection, and even grade 3 lesions were distinguished only by polyuria.

\section{PHENACETIN DERIVATIVES}

Under the conditions of the experiment this group of compounds was more nephrotoxic than aspirin and its derivatives, producing more severe renal damage and at lower dose levels (Fig. 5). Increasing doses of phenacetin derivatives produced conspicuous increases in renal damage in contrast to the effects produced by increasing doses of aspirin derivatives.

The nephrotoxic effect of phenacetin derivatives seems to result from the para arrangement on the benzene ring of the hydroxyl and amino groups. Thus $p$-aminophenol is nephrotoxic while $m$-aminophenol and $o$-aminophenol are not. Substitution on the hydroxyl group by conversion to the ether also removes the nephrotoxic effect, thus $p$-phenetidine is not nephrotoxic. These effects are also observed with 3, 4-dihydroxyaniline and its ethers (Table I). 3, 4-Dihydroxyaniline and 4-hydroxy-3methoxyaniline are extremely nephrotoxic, but 3-hydroxy-4-

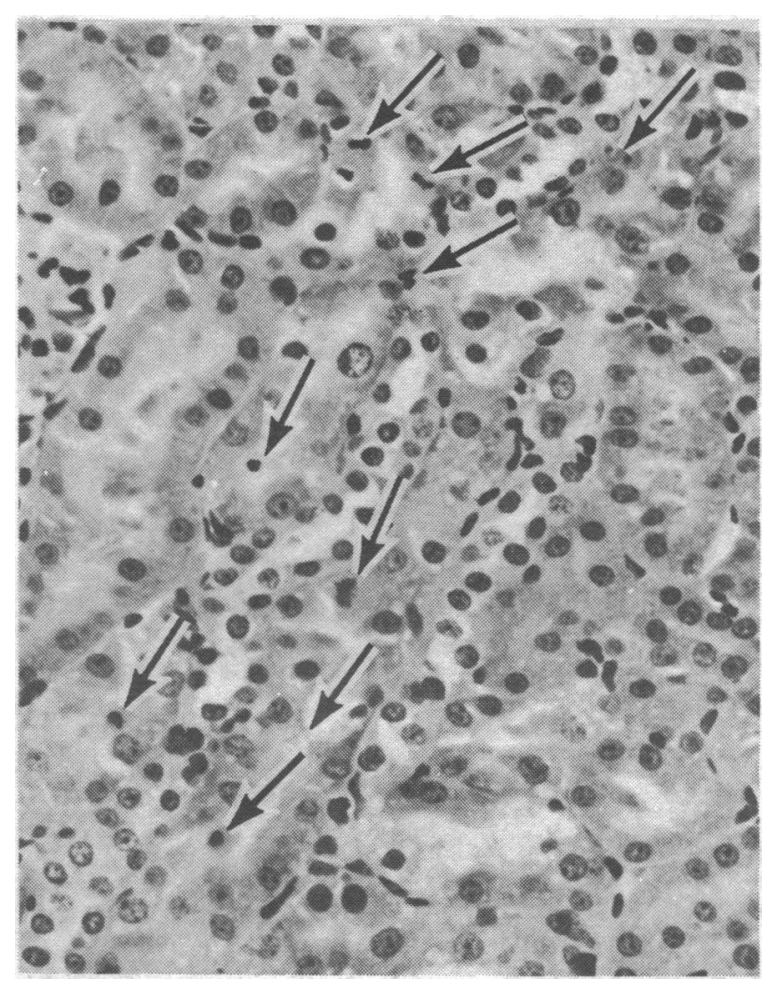

FIG. 1-Rat kidney. Necrosis of individual cells of the proximal convoluted tubules. Necrotic cells and mitoses are indicated by arrows. Grade 1. (H. \& E. $\nvdash 370$.) 
methoxyaniline and 3, 4-dimethoxyaniline are both nonnephrotoxic.

Modification of the amino group also affects nephrotoxicity. One methyl group substituted on the amino group increases nephrotoxicity. An acetyl group reduces it; $\mathrm{N}$-acetyl-p-amino-

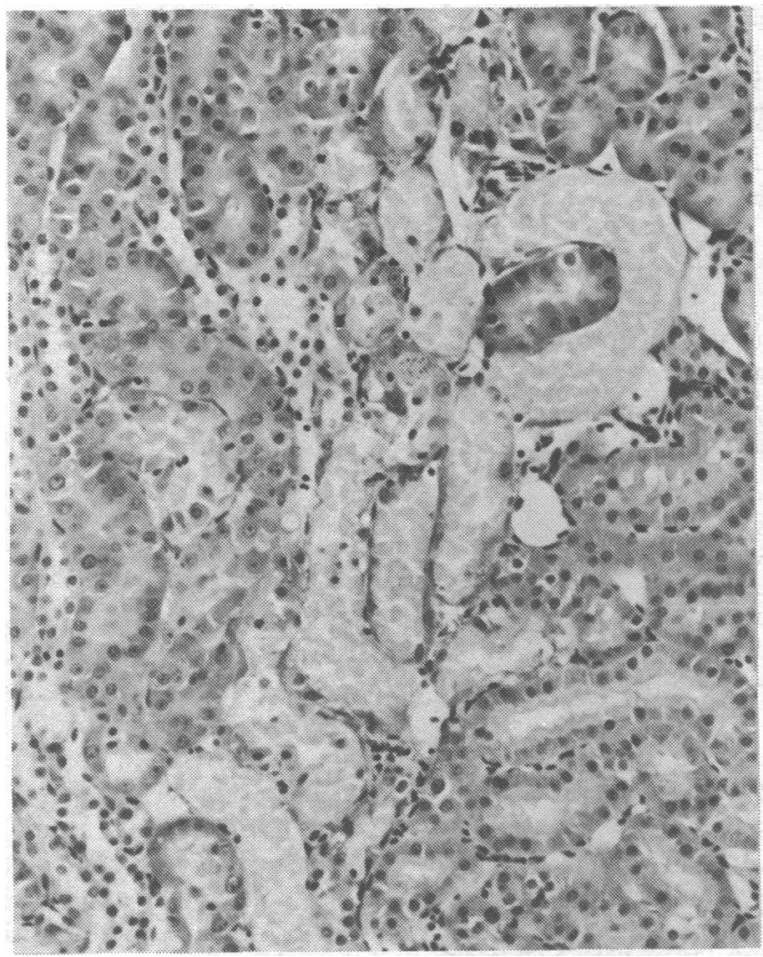

FIG. 2-Rat kidney. Necrosis of all cells in adjoining proximal convoluted tubules. The necrotic tubules are surrounded by viable tubules. Grade 2. (H. \& E. × 230.)

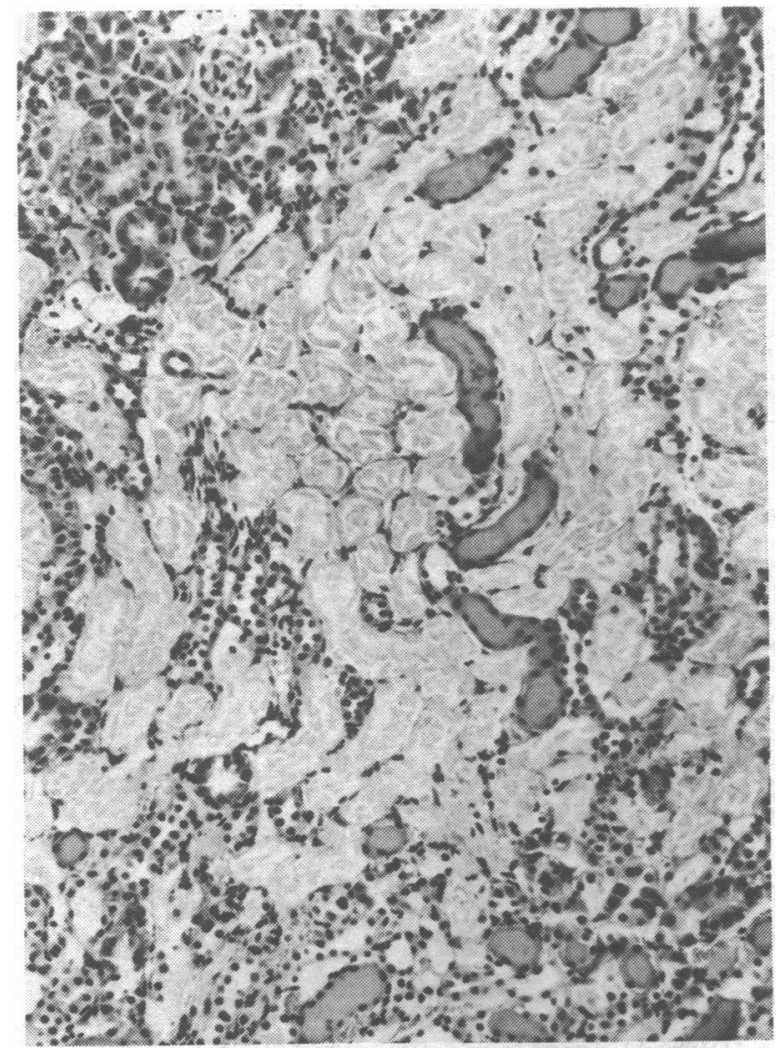

FIG. 3-Rat kidney. Necrosis of the distal third of the proximal convoluted tubule. Grade 3. (H. \& E. $\times 100$.) phenol (paracetamol) did not induce renal damage. However, O-substitution of an acetyl group does not affect nephrotoxicity.

There were five nephrotoxic compounds related to phenacetin in which a para arrangement of hydroxyl and amino groups was not present-aniline, 2-hydroxyphenetidine, N-methylaniline, phenylhydroxylamine, and 2,6-dihydroxyaniline. The first two were minimally nephrotoxic, the third and fourth moderately so, and the fifth was as nephrotoxic as $p$-aminophenol. Chemical analysis of urinary excretion products showed that $p$-aminophenol was formed from aniline.

Urinary excretion products were measured for a number of compounds. After a single dose of $p$-aminophenol $(2 \mathrm{mM} / \mathrm{kg})$ about $60_{\%}^{\circ}$ was $\mathrm{N}$-acetylated and conjugated and some $20^{\circ}{ }_{1}$ excreted as non-acetylated but conjugated $p$-aminophenol; $0.05 \mathrm{mg}$ of free $p$-aminophenol could be detected after extraction of a neutral unhydrolysed sample of urine.

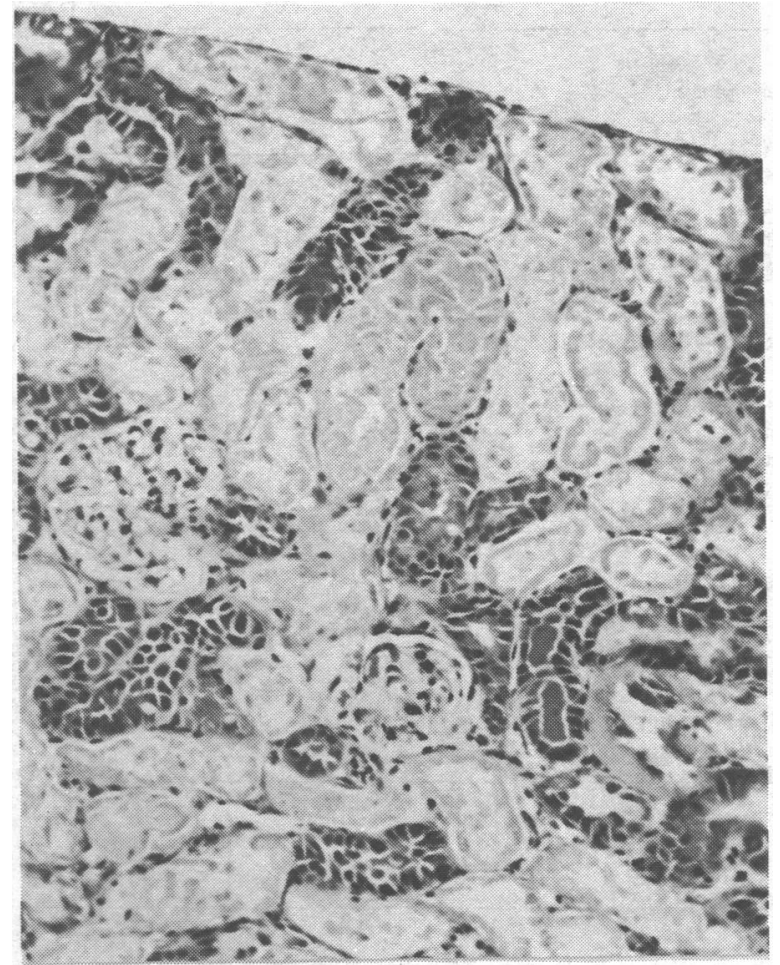

FIG. 4-Rat kidney. Necrosis extending over the proximal convoluted tubule. Grade 4. (H. \& E. $>230$.)

Severity

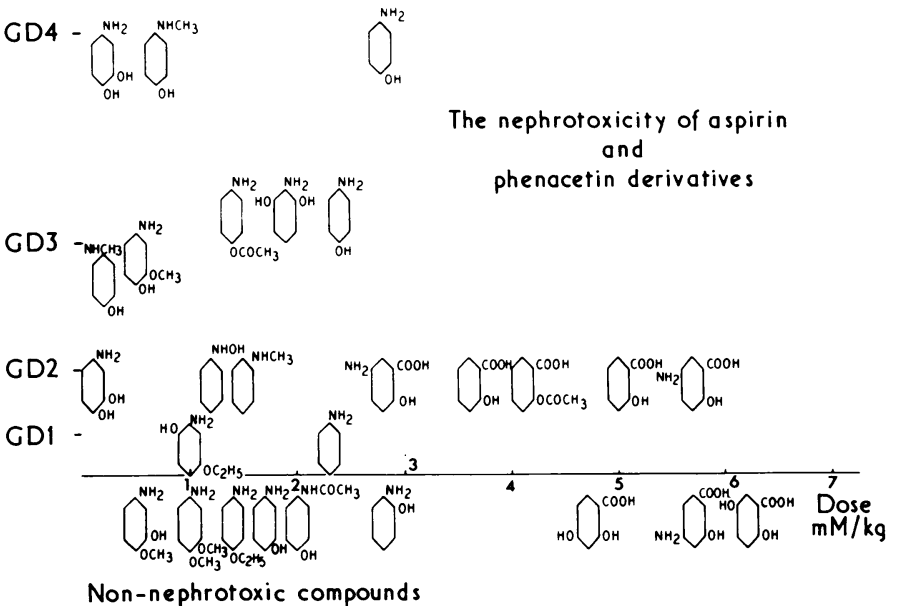

FIG. 5-Schematic comparison of the nephrotoxicity of aspirin and phenacetin derivatives. It will be noted that phenacetin derivatives are nephrotoxic at lower doses than the salicylates, and that higher doses of the same phenacetin derivative produced more severe renal damage. 


\section{ASPIRIN DERIVATIVES}

Both aspirin and sodium salicylate were nephrotoxic in high intravenous doses, but not in doses below $3 \mathrm{mM} / \mathrm{kg}$. Above this dose relatively little variation in the degree of renal damage was produced by increasing doses of these compounds. p-Aminosalicylic acid and the two dihydroxybenzoic acids investigated were not nephrotoxic. A sixth compound, $m$-aminosalicylic acid (5-aminosalicylic acid), which may be considered as a derivative of both phenacetin and aspirin, produced necrosis of proximal convoluted tubules and of the renal papilla.

\section{Discussion}

The results indicate that in this experimental model phenacetin derivatives are much more nephrotoxic than aspirin and its derivatives. The results supplement earlier observations (Green et al., 1969) which suggested that the toxicity of some phenacetin derivatives might be related to the para arrangement of amino and hydroxyl groups on the benzene ring. Since phenacetin cannot be made water soluble it was not studied in this experiment, but findings with $\mathrm{N}$-acetyl-p-aminophenol and $p$ phenetidine indicate that the acetylation of the amino group and alkylation of the hydroxyl group of the phenacetin molecule each independently masks the nephrotoxicity due to the para arrangement of amino and hydroxyl groups. N-acetyl-paminophenol was not nephrotoxic in this acute experiment; this, of course, does not necessarily imply that it could not contribute to analgesic renal damage in man, or that it might not under other circumstances be deacetylated to nephrotoxic $p$-aminophenol. Indeed, $\mathrm{N}$-acetyl-p-aminophenol labelled on the acetyl group can be shown to exchange acetyl groups after being fed to certain species (Smith, Davison, and Sodd, 1956). However, it is consistent with clinical (Prescott, Roscoe, Wright, and Brown, 1971) and experimental (Boyd and Bereczky, 1966) findings that acute poisoning by $\mathrm{N}$-acetyl-paminophenol is associated with hepatic rather than renal damage.

A number of compounds related to phenacetin but lacking the para arrangement of the amino and hydroxyl groups were found to be nephrotoxic. These were aniline, $\mathrm{N}$-methylaniline, phenylhydroxylamine, 2-hydroxyphenetidine, and 2, 6-dihydroxyaniline. $p$-Aminophenol was found in the urine after administration of aniline, and this compound is known to be formed in the metabolism of phenylhydroxylamine (Banthorpe, 1968). Methods have yet to be devised to determine the metabolites of 2-hydroxyphenetidine and 2,6-dihydroxyaniline.

It is true that neither $p$-aminophenol nor any other nephrotoxic metabolite has been shown to be derived from phenacetin in man. Nor is this to be expected; large single overdoses of phenacetin have not been shown to be nephrotoxic, and were $p$-aminophenol formed, such doses should invariably be nephrotoxic. Enzymes to convert phenacetin to $p$-aminophenol exist in the body and are known to be involved in the metabolism of phenacetin. A transient diversion of the metabolism of phenacetin to the production of $p$-aminophenol is thus consistent with the occasional acute, severe renal damage which is believed to develop during long-continued overdosage with analgesic compounds.

It is noteworthy that aspirin and sodium salicylate, rather than their related compounds, are nephrotoxic in high doses. Aspirin causes necrosis of proximal convoluted tubules, similar to lesions produced by sodium salicylate (Robinson, Nichols, and Taitz, 1967), and does not lead to the renal papillary necrosis which has developed in protracted high-dose feeding experiments (Nanra and Kincaid-Smith, 1970). Similarly, necrosis of proximal convoluted tubules rather than papillary necrosis (White and Mori-Chavez, 1952) was found with N-methylaniline.

In further studies it has been found that necrosis of proximal convoluted tubules can be produced by a single intravenous injection of $\mathrm{N}$-phenylanthranilic acid and of 1,2,3, 4-tetrahydroquinoline, which under other regimens have been shown to produce renal papillary necrosis (Hardy, 1970; Rehns, 1901). This unexpected finding emphasizes the importance of ascertaining the factors responsible for medullary localization of toxic nephron damage, and suggests that characterization of analgesic renal damage as a primarily medullary lesion with secondary cortical damage (Kincaid-Smith, 1967) may be an unduly simple approach to an extremely complex problem. Localized necrosis may be only the most obvious manifestation of damage to the whole nephron. This is indicated by the simultaneous onset of convoluted tubule and renal papillary necrosis after a single intravenous injection of $m$-aminosalicylic acid (Calder, Funder, Green, Ham, and Tange, 1971), by electron microscopic appearances of severe damage in Henle's loops in rats in which necrosis of proximal convoluted tubules has been induced by p-aminophenol (Funder, Green, Ham, and Tange, 1971), and by functional evidence of distal nephron involvement after uranium-induced injury to the proximal nephron (Bowman and Foukes, 1970).

\section{References}

Banthorpe, D. V. (1968). The Chemistry of the Amino Group, ed. S. Patai, p. 585. London, Interscience Publishers.

Bowman, F. J., and Foukes, E. C. (1970). Toxicity and Applied Pharmacology, 16,391 .

Boyd, E. M., and Bereczky, G. M. (1966). British fournal of Pharmacology and Chemotherapy, 26, 606

Calder, I. C., Funder, C. C., Green, C. R., Ham, K. N., and Tange, J. D. (1971). In preparation.

Funder, C. C., Green, C. R., Ham, K. N., and Tange, J. D. (1971). Australian and New Zealand fournal of Medicine, 1 . In press.

Green, C. R., Ham, K. N., and Tange, J. D. (1969). British Medical fournal, 1,162 .

Hardy, T. L. (1970). British Fournal of Experimental Pathology, 51, 348.

Kincaid-Smith, P. (1967). Lancet, 1, 859.

Koutsaimanis, K. G., and de Wardener, H. E. (1970). British Medical fournal, 4, 131

Nanra, R. S., and Kincaid-Smith, P. (1970). British Medical fournal, 3, 559. Prescott, L. F., Roscoe, P., Wright, N., and Brown, S. S. (1971). Lancet, 1,519 .

Rehns, J. (1901). Archives internationales de pharmacodynamie et de thérapie, 8, 199.

Robinson, M. J., Nichols, E. A., and Taitz, L. (1967). Archives of Pathology,

84, 224.
Smith, P. K., Davison, C., and Sodd, M. A. (1956). Proceedings of the International Physiological Congress, Brussels, p. 836.

Tompsett, S. L. (1969). Annals of Clinical Biochemistry, 6, 81.

White, J., and Mori-Chavez, P. (1952). Fournal of the National Cancer Institute, 12, 777 